\title{
Design and Implementation of a Teaching Assistance Platform for College Students Based on ASP.NET
}

\author{
https://doi.org/10.3991/ijet.v14i12.10707 \\ Yu Yan \\ Chongqing Technology and Business University, Chongqing, China \\ saying 327 esina.com
}

\begin{abstract}
Teaching assistance platforms for college students greatly promote the quality and resource utilization of college teaching, marking the direction of information-based modern higher education. This paper designs a student-centered, teacher-led college student teaching assistance platform. Following the object-oriented design method, the SQL was taken as the database, the ASP.NET was selected as the server-end language, and the ADO.NET was adopted as the database access technology. The platform structure and the eHomework module were cited as examples to detail the design and implementation of the platform. The analysis shows that the platform can fully support all aspects of teaching and satisfy the specific requirements of college teaching. The research findings provide impetus to scientific teaching in colleges.
\end{abstract}

Keywords-ASP.NET, SQL database, Teaching assistance platform, Design and implementation

\section{Introduction}

With the development and integration of modern network technology, computer information technology and modern educational technology, the college teaching concepts and teaching methods have undergone tremendous changes. Building an open network teaching platform that can break traditional education's limitations in time, space and region can effectively promote college teaching and rational use of teaching resources [1], and it's an important way to realize the informatization and modernization of higher education. Therefore, many experts and scholars, universities and educational service enterprises at home and abroad are committed to the design and development of the teaching assistance platform.

College student teaching assistance platform [2] uses online education technology to make up for the shortcomings of traditional teaching. The platform is not limited by teaching time or venue, it can enhance students' sense of participation, improve their initiative, make the teaching methods more scientific, promote information communication between students and teachers, realize resource sharing and online teaching, and finally achieve the teaching automation. In 1997, Murray Goldberg of Canada developed the Web CT network teaching platform, a network teaching courseware development and management system based on Web browser, the platform has unique 
selective publishing function and powerful teaching tracking function, now it has become one of the two most popular online education platforms worldwide [3]. In our country, the research and development of the teaching assistance platform for college students started relatively late compared with foreign countries. Many universities and manufacturers have carried out research and development on teaching assistance platforms, such as the online teaching platform of Peking University, ontoedu.pku.edu.cn, and Tsinghua University's online education platform, learn.tsinghua.edu.cn, etc. [4]. In addition, due to function, price and other reasons, the promotion effects of some foreign mature online teaching platforms in China are not ideal [5].

This paper adopted the ASP.NET technology to design a student-centered, teacherled teaching assistance platform for college students, it analyzed the requirements of the platform from the perspective of user experience, and divided the functional modules in detail, using SQL as the database, ASP.NET as the server end language, ADO.NET as database access technology, it achieved various functions of the system.

\section{Related Technologies for Platform Construction}

\section{$2.1 \quad$.NET Framework}

.NET is a design framework developed by Microsoft that supports the development platform environment of various user terminals [6]. The .NET framework consists of five parts: .NET development platform, .NET server, .NET basic services, .NET terminal device and .NET user experience [7]. The .NET development platform includes ASP.NET, .NET development tools, and the .NET Framework. The .NET Framework is the most important basic framework for .NET and the core of .NET software construction. Figure 1 shows the .NET Framework hierarchy [8].

ASP.NET is a component of the .NET development platform. It is a development platform based on the common language runtime library which has high efficiency and can provide developers with a variety of programming languages. The configuration system is layered by text, simplifying the process of configuration information changing [9].

ADO.NET is based on XML and consists of a series of database related classes and interfaces [10], including two core components of .NET Framework Data Provider and DataSet, which provide a brand-new data access method based on the .NET platform [11]. Figure 2 shows the structure of ADO.NET. 


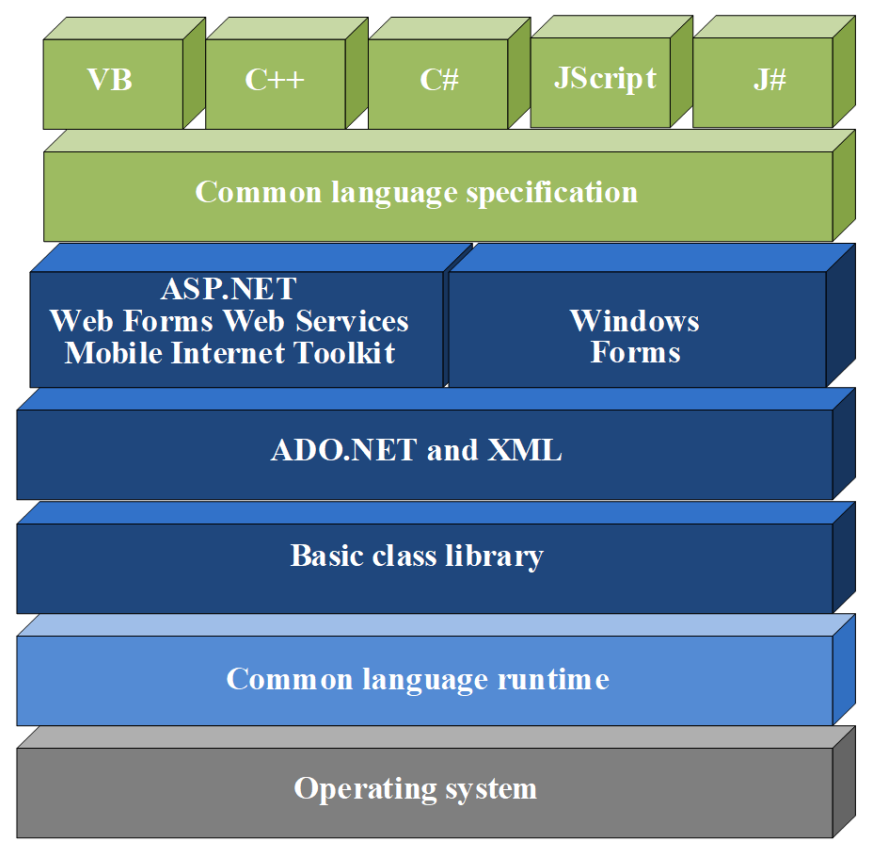

Fig. 1. .NET Framework hierarchy

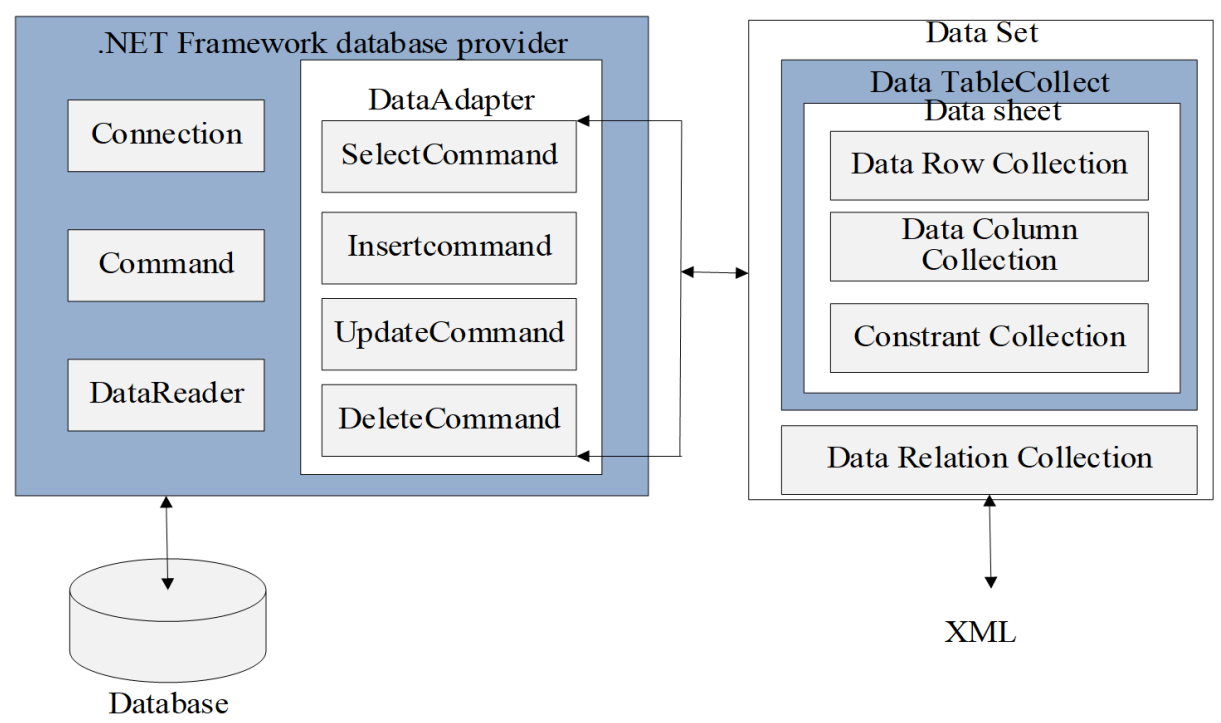

Fig. 2. Structure diagram of ADO.NET 


\subsection{SQL server}

SQL Server is a comprehensive relational database management system designed for distributed client/server computing [12]. It has the advantages of high scalability, high security, good scalability and simple operation [13].

\section{Design and Implementation of College Student Teaching Assistance Platform Based on ASP.NET Technology}

\subsection{Platform requirements analysis}

The requirements of the platform can be divided into two levels of functional and non-functional requirements [14-16]. The essence of the platform is to determine the requirements of each function and related business of the platform based on the analysis and investigation of the design objects [17]. The users of the college teaching assistance platform are mainly students and teachers. Therefore, on the one hand, when designing the platform, this paper referred to the design experiences of some successful domestic and foreign network teaching assistance platforms [24], on the other hand, it also conducted investigation and analysis on users of the teaching platform, and finally determined functions of the platform and module division of the teaching assistance platform.

Teacher users: As knowledge transferrers and guiders in the teaching activities, teachers are one of the important participants in the college student teaching assistance platform. The main requirements of the teaching platform include: upload, modify and delete course-related teaching resources according to the teaching plan and requirements; create natural classes like traditional classes and manage them, and publish relevant information such as course information and homework to students; review student's homework, communicate and discuss with them about their homework and other learning questions; create, modify, and delete exam question bank according to teaching requirements; conduct online tests on students; and manage students' achievements. Figure 3 shows the main functional requirements of the teacher users.

Student users: Students are the main users of the college student teaching assistance platform. They can use the platform to learn, download related teaching resources provided by teachers, including courseware, homework, etc.; they can view the homework assigned by teachers, upload the completed homework, browse the course arrangement, teachers' comments on their homework, as well as the Q\&A of other students; meanwhile, they can also ask questions about the content they don't understood, search for relevant knowledge points in the question bank to conduct selftests, and view the announcement information issued by the teachers and the class. Figure 4 shows the main functional requirements of the student user.

Platform administrator users: The system administrator's main responsibility is to ensure that the system can be operated safely to supervise and maintain all aspects of the system. Therefore, the system administrators have all functions of other users, 
and after login, they can manage all aspects of the platform, including delete improper messages, manage announcements, teaching resources, and question bank according to the accepted commissions.

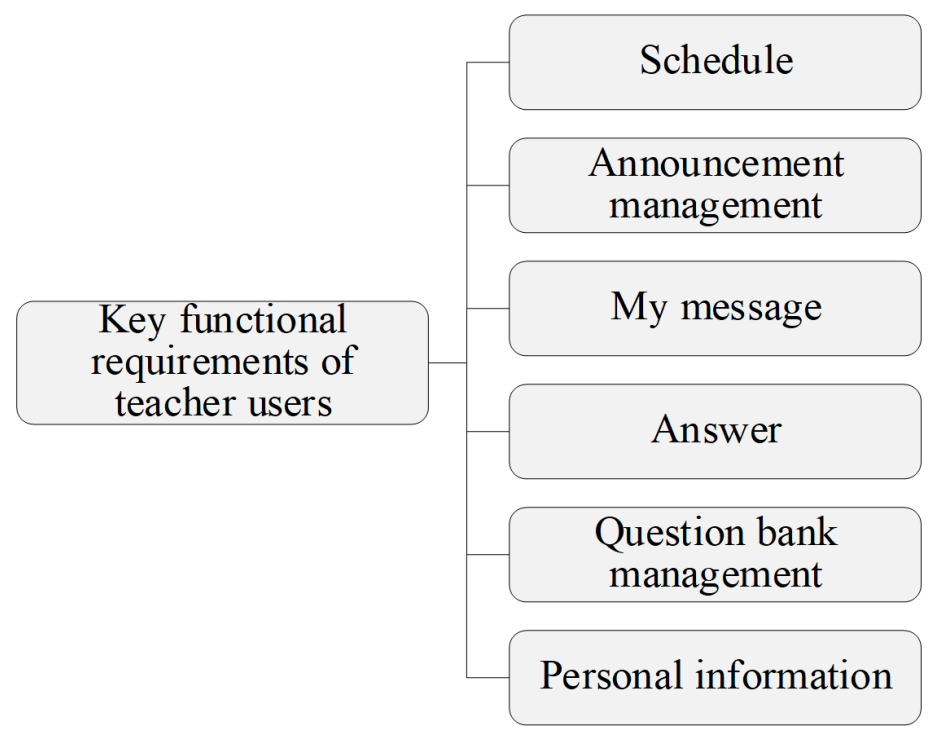

Fig. 3. Main functional requirements of teacher users

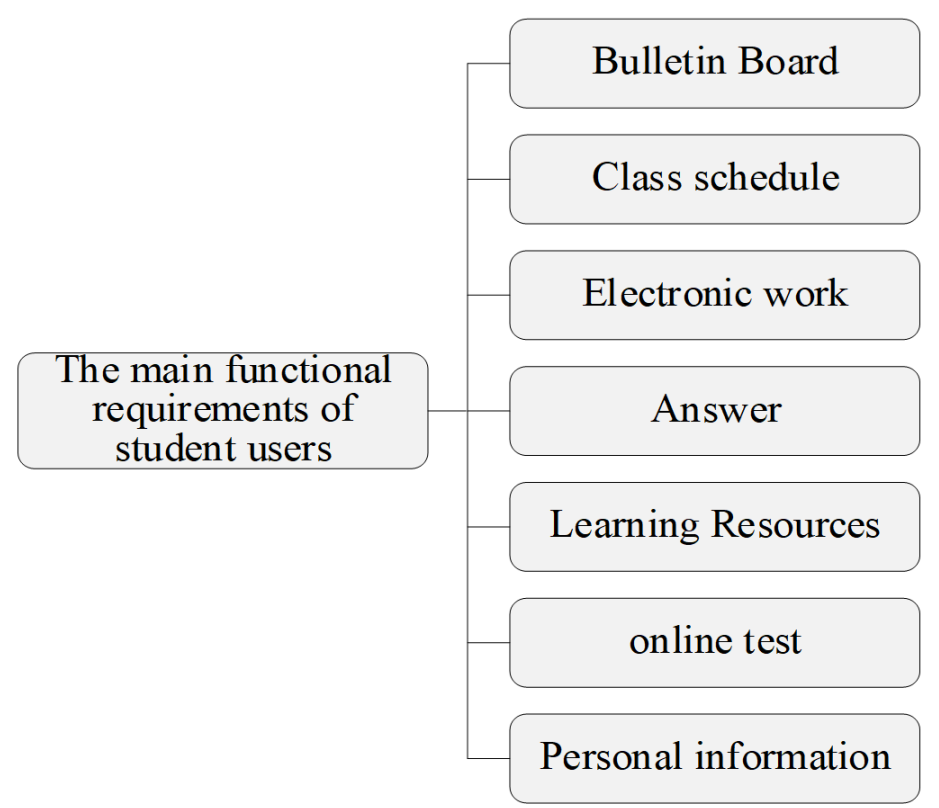

Fig. 4. Main functional requirements of student users 


\subsection{Platform function module division}

According to the analysis of the user function requirements of the college student teaching assistance platform, we can divide the platform into six modules: teaching resource sharing, question bank management, news announcement, online Q\&A, ehomework and online testing, as shown in Figure 5.

1. Teaching resource sharing module. Teachers can upload relevant teaching resources through this module and manage the teaching resources. Students can browse the teaching resources online or download them as needed.

2. Question bank management module. Teachers can create, modify, and delete relevant contents in the question bank through this module. At the same time, the platform will automatically organize and publish test papers according to the teaching requirements of the teachers.

3. News announcement module. The system administrator can publish and manage school-related announcements and news through the news announcement module. Teachers can also use this module to publish the announcements such as course schedules and homework assignments, etc.

4. Online Q\&A module. Students can edit and upload questions they encountered during study, and they can answer and discuss question raised by other students, teachers can participate in the question response and discussion as well.

5. E-homework. Teachers can post homework to students and correct the homework in this module, students can download the homework and upload their completed homework, meanwhile, teachers and students can also discuss the content of the homework assignments.

6. Online testing. Students can choose online self-tests of different chapters or knowledge points according to their own shortcomings. Teachers can also manually or automatically organize the exam papers according to the teaching requirements, and evaluate the students' learning situations. 


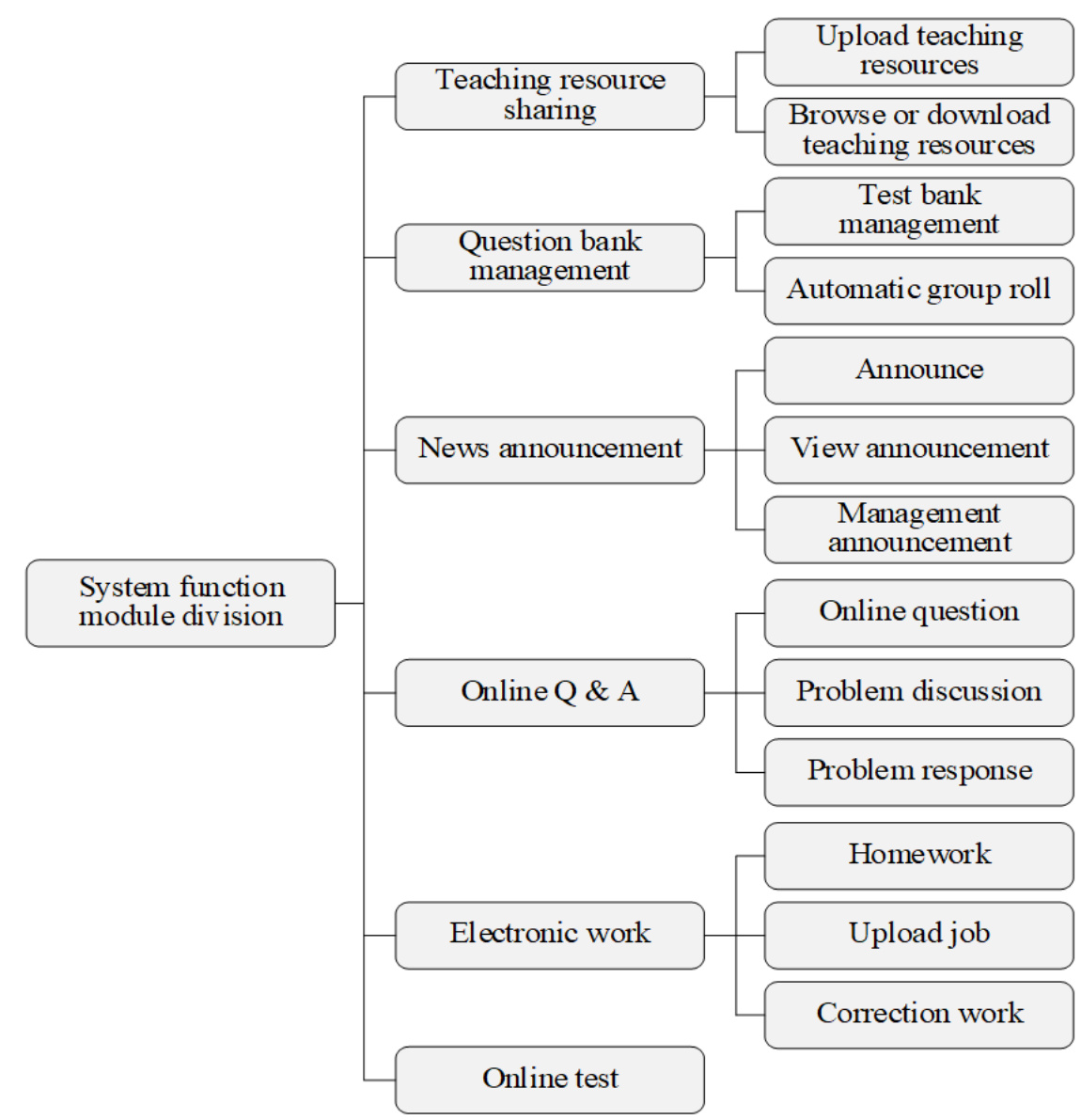

Fig. 5. System function module division

\subsection{Platform design and implementation}

This paper took the platform structure and the e-homework module function as examples to illustrate the design and implementation of the system.

Platform structure design and implementation: The teaching platform adopts a four-layer B/S structure mode consisted of presentation layer, logic layer, data access layer, and storage layer. Wherein the presentation layer offers the user interface of the application program, which is realized through the WEB FORMS of ASP.NET, and browser is used to facilitate the users. The logic layer is an important layer in the hierarchical model, it's located in the middle and can realize business functions of the application program. The access to the database data is realized by ADO.NET. The data access layer should be able to implement all data-related operations such as returning data sets from the database, adding updated data to the database, etc. This layer mainly uses ADO.NET technology to realize the interaction with the database. 
The data storage layer mainly provides data storage and query functions. The platform uses SQL Server to process all data access procedures to ensure data security and improve storage efficiency. Figure 6 shows the platform's multi-layer architecture.

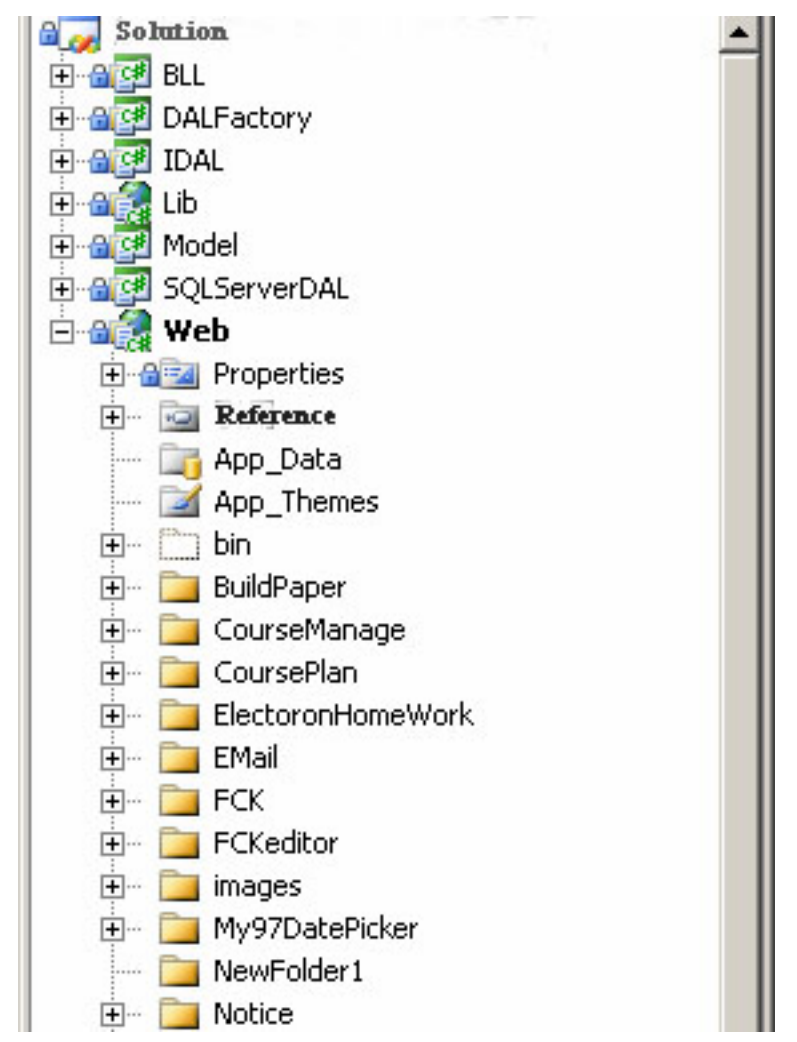

Fig. 6. Platform multi-layer architecture

Design and implementation of the e-homework module: The main function of this module is to promote the communication between teachers and students through the completion of e-homework. Teachers can correct and review students' homework, reply to their feedback in a timely manner, and publish student homework that had been well completed for other students' references; meanwhile, in order to prevent plagiarism, the platform also provides a homework similarity detection function, teachers can send plagiarism feedback to the students if plagiarism is detected, and ask them to correct it. Students can complete the homework and upload it after receiving the notification. Before the homework is corrected by teachers, students can modify the deficiencies in the homework at any time. After receiving the teacher's comments of the homework, students can communicate with the teacher about the existing problems. Figure 7 shows the business flow of the student user function in the ehomework module, and Figure 8 shows the student homework submission function interface. 


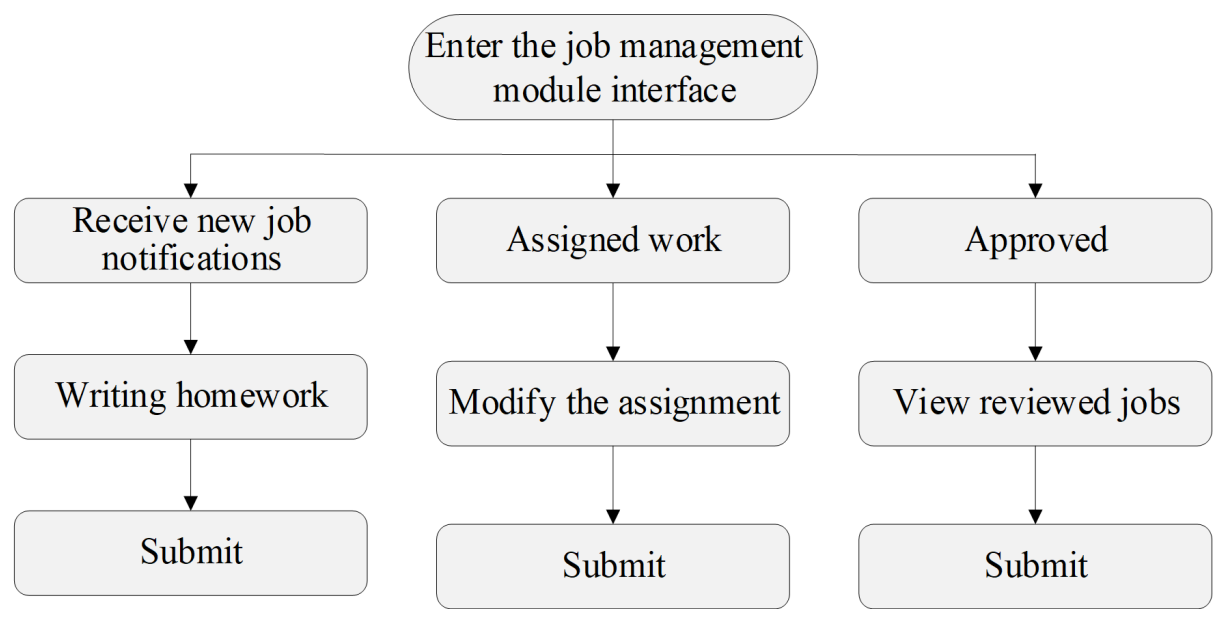

Fig. 7. Student e-homework function business flow

\section{Home Homework}

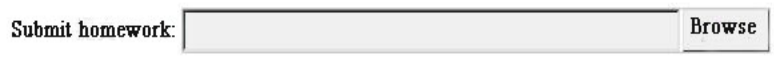

Course Title: $\longdiv { \mathrm { C } + + } \vee$

Submit

Fig. 8. Student e-homework submission function interface

Figure 9 shows the business flow of the teacher user function in the e-homework module, and Figure 10 shows the teacher management function interface.

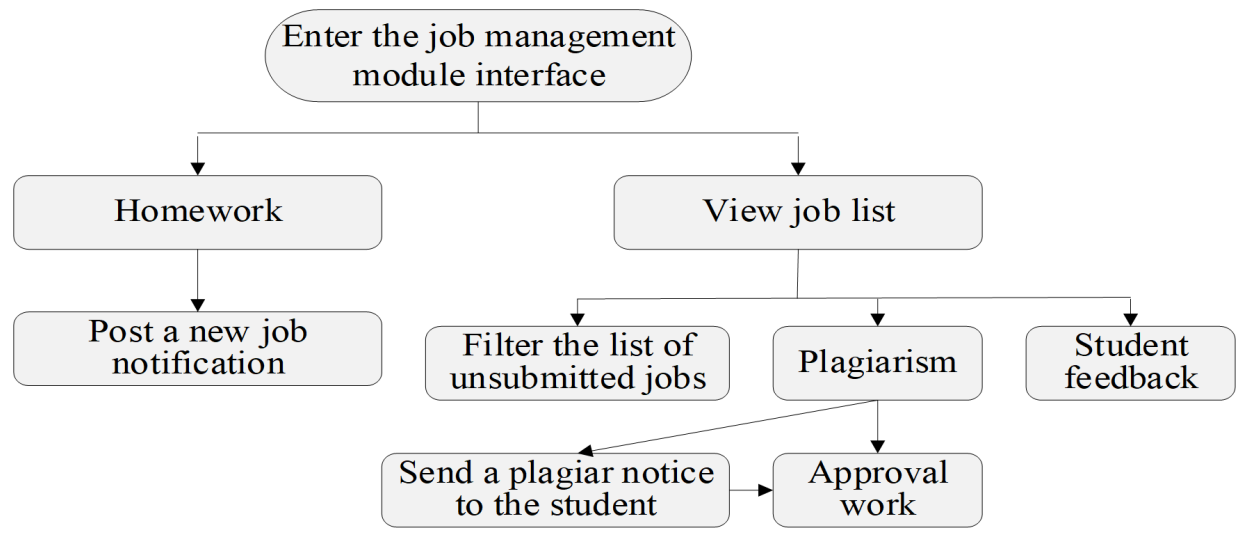

Fig. 9. Teacher e-homework module business flow 


\begin{tabular}{|c|c|c|c|c|c|c|c|}
\hline Home I & job & & & & & & \\
\hline \multirow{8}{*}{$\begin{array}{l}\text { My job } \\
\text { Homework } \\
\text { Job review } \\
\text { Job correction } \\
\text { Job statistics }\end{array}$} & & & & & & & \\
\hline & Numbering & student ID & Class & Course Title & Date & Status & Operating \\
\hline & Job-001 & 3015216012 & C2015-01 & $\mathrm{C}++$ & 2018-11-25 & Pending review & Correction \\
\hline & Job-002 & 3015216014 & C2015-01 & $\mathrm{C}++$ & 2018-11-23 & Pending review & Correction \\
\hline & Job-003 & 3015216015 & C2015-01 & $\mathrm{C}++\cdots$ & 2018-11-27 & Pending review & Correction \\
\hline & Job-004 & 3015216023 & C2015-01 & $\mathrm{C}++$ & $2+15 \ldots . .$. & Unsubmitted & Correction \\
\hline & Job-005 & 3015216026 & C2015-01 & $\mathrm{C}++$ & 2018-11-28 & Pending review & Correction \\
\hline & Job-006 & 3015216029 & C2015-01 & $\mathrm{C++}$ & $24+-3=2$ & Unsubmitted & Correction \\
\hline
\end{tabular}

Fig. 10.Teacher management function interface

\section{Conclusion}

The network teaching assistance platform can enrich teaching content, improve students' interest in learning, and promote communication between teachers and students. This paper focused on the design and implementation of college student teaching assistance platform. The specific conclusions are as follows:

1. From the perspective of teacher, student, and administrator, the three main user groups of the platform, this paper analyzed the specific requirements of the platform in detail.

2. Based on the analysis of platform function requirements, the system is divided into six functional modules, and the functions of each functional module are briefly analyzed.

3. Using SQL as the database and ASP.NET as the server-end language, the ADO.NET database access technology was adopted to design and implement the platform's structural functions and e-homework module functions.

\section{Acknowledgement}

This work is supported by 2015 Annual Project under Chongqing Education Science Programs During the 12th Five-year Planning Period. Project No.: 2015-GX066.

\section{References}

[1] Guichon, N. (2010). Preparatory study for the design of a desktop videoconferencing platform for synchronous language teaching. Computer Assisted Language Learning, 23(2): 169-182. https://doi.org/10.1080/09588221003666255

[2] Osipov, I.V., Prasikova, A.Y., Volinsky, A.A. (2015). Participant behavior and content of the online foreign languages learning and teaching platform. Computers in Human Behavior, 50: 476-488. https://doi.org/10.1016/j.chb.2015.04.028 
[3] Tian, Y., Xiao, W., Li, C., Liu, Y., Qin, M., Wu, Y., Xiao, L., Li, H.L. (2014). Virtual microscopy system at Chinese medical university: an assisted teaching platform for promoting active learning and problem-solving skills. BMC Medical Education, 14(1): 74. https://doi.org/10.1186/1472-6920-14-74

[4] Chen, N., Trowbridge, C.G., Jr, J.B.J. (2010). Seeking sustainable solutions: using an attractor simulation platform for teaching multistakeholder negotiation in complex cases. Negotiation Journal, 26(1): 49-68. https://doi.org/10.1111/j.1571-9979.2009.00253.x

[5] Amde, W., Sanders, D., Lehmann, U. (2014). Building capacity to develop an african teaching platform on health workforce development: a collaborative initiative of universities from four sub saharan countries. Human Resources for Health, 12(1): 31. https://doi.org/10.1186/1478-4491-12-31

[6] Rong, R. (2014). Research on web site construction of quality course based on network teaching platform. International Journal of Technology Management, 89-92. https://doi.org/10.2495/gen130501

[7] Sadow, J.D. (2002). The internet as a delivery platform for audio-visual teaching. European Political Science, 1(2): 62-64. https://doi.org/10.1057/eps.2002.12

[8] So, H.J., Lossman, H., Lim, W.Y., Jacobson, M.J. (2009). Designing an online video based platform for teacher learning in singapore. Australasian Journal of Educational Technology, 25(3): 440-457. https://doi.org/10.14742/ajet.1144

[9] Guichon, N. (2010). Preparatory study for the design of a desktop videoconferencing platform for synchronous language teaching. Computer Assisted Language Learning, 23(2): 169-182. https://doi.org/10.1080/09588221003666255

[10] Lambert, J. (2013). Teaching an aerospace engineering design course via virtual worlds: a comparative assessment of learning outcomes. Computers \& Education, 60: 288-298. https://doi.org/10.1016/j.compedu.2012.07.012

[11] Richardson, W.K., Segal, D.M. (1998). Teaching analysis of interaction in the $2 \times 2$ factorial design. Teaching of Psychology, 25(4): 297-299.

https://doi.org/10.1080/00986289809709722

[12] Velthuis, C., Fisser, P., Pieters, J. (2015). Collaborative curriculum design to increase science teaching self-efficacy: a case study. The Journal of Educational Research, 108(3): 217-225. https://doi.org/10.1080/00220671.2013.878299

[13] Mcnulty, J.A., Sonntag, B., Sinacore, J.M. (2010). Evaluation of computer-aided instruction in a gross anatomy course: a six-year study. Anatomical Sciences Education, 2(1): 2-8. https://doi.org/10.1002/ase.66

[14] Li, Y. (2018). Design and implementation of intelligent travel recommendation system based on internet of things, Ingénierie des Systèmes d'Information, 23(5): 159-173. https://doi.org/10.3166/ISI.23.5.159-173

[15] Abel, M.H., Saleh, M. (2017). MEMORAe: un système d'information support d'un écosystème apprenant, Ingénierie des Systèmes d'Information, 22(6): 53-69. https://doi.org/10.3166/isi.22.6.53-69

[16] Wang, C., Wang, J.H., Sun, X.H., Wang, F.S. (2018). A novel soil nutrient classification method based on hadoop platform, Revue d'Intelligence Artificielle, 32(S1): 25-40. https://doi.org/ 10.3166/RIA.32.S1.25-40

[17] Menulty, J.A., Halama, J., Dauzvardis, M.F., Espiritu, B. (2000). Evaluation of web-based computer-aided instruction in a basic science course. Academic Medicine, 75(1), 59-65. https://doi.org/10.1097/00001888-200001000-00016

[18] Sleeman, D.H. (1983). 16-inferring student models for intelligent computer-aided instruction. Machine Learning, 1(3): 483-510. https://doi.org/10.1007/978-3-662-12405-5 16 
[19] Dirin, A., Laine, T.H. (2018). Towards an adaptive study management platform: Freedom through personalization, CSEDU 2018 - Proceedings of the 10th International Conference on Computer Supported Education, 1: 432-439.

https://doi.org/10.5220/0006788104320439

[20] Kayal, S., Das, B. (2017). E-learning system of Asia through open courseware (OCW) and educational resources (OER) for universal access to knowledge and information, International Journal of Web-Based Learning and Teaching Technologies, 12(2): 43-54. https://doi.org/10.4018/ijwltt.2017040103

[21] Monteiro, E.J.M., Costa, C., Oliveira, J.L. (2016). A cloud architecture for teleradiologyas-a-service, Methods of Information in Medicine, 55(3): 203-214. https://doi.org/10.3414/me14-01-0052

[22] Fang, H. (2014). Study on the assistance of microblogging in english literature teaching, Lecture Notes in Electrical Engineering, 269 LNEE: 1699-1705. https://doi.org/10.1007/978-94-007-7618-0 195

[23] Xu, J.L., Liu, X.J., Wang, H.X., Zhang, J.Q., Liu, Y.Y., Zhang, T. (2014). International Journal of Emerging Technologies in Learning, 9(8): 42-44

[24] Wang, Q., Tang, Z., Knezevic, I., Yu, J., Karady, G. (2016). Power system protection education and digital relay training based on a physical platform, NAPS 2016 - 48th North American Power Symposium, Proceedings: 7747884.

https://doi.org/10.1109/naps.2016.7747884

\section{$7 \quad$ Author}

Yu Yan, male, born in February 1986, a holder of a Master's degree, is working as an instructor in Modern International Art and Design Academy (MIADA), Chongqing Technology and Business University (CTBU), with the research interest in ideological and political education.

Article submitted 2019-04-19. Resubmitted 2019-05-25. Final acceptance 2019-05-27. Final version published as submitted by the authors. 